\title{
Analysis of Nucleotide Variations in Genes of Iron Management in Patients of Parkinson's Disease and Other Movement Disorders
}

\author{
Emanuela Castiglioni, ${ }^{1}$ Dario Finazzi, ${ }^{2}$ Stefano Goldwurm, ${ }^{3}$ \\ Gianni Pezzoli, ${ }^{3}$ Gianluca Forni, ${ }^{4}$ Domenico Girelli, ${ }^{5}$ Federica Maccarinelli, ${ }^{2}$ Maura Poli, ${ }^{2}$ \\ Maurizio Ferrari, ${ }^{1,6,7}$ Laura Cremonesi, ${ }^{1}$ and Paolo Arosio ${ }^{2}$ \\ ${ }^{1}$ Genomic Unit for the Diagnosis of Human Pathologies, Center for Genomics, Bioinformatics and Biostatistics, \\ San Raffaele Scientific Institute, 20132 Milan, Italy \\ ${ }^{2}$ Sezione di Chimica, Facoltà di Medicina, Università di Brescia \& Terzo Laboratorio di Analisi Chimico Cliniche, \\ Spedali Civili di Brescia, 25123 Brescia, Italy \\ ${ }^{3}$ Centro Parkinson e Disturbi del Movimento, Istituti Clinici di Perfezionamento, 20126 Milan, Italy \\ ${ }^{4}$ Centro della Microcitemia e Anemie Congenite, Ospedale Galliera, 16128 Genova, Italy \\ ${ }^{5}$ Department of Clinical and Experimental Medicine, Section of Internal Medicine, University of Verona, 37134 Verona, Italy \\ ${ }^{6}$ Università Vita-Salute San Raffaele, 20132 Milan, Italy \\ ${ }^{7}$ Diagnostica e Ricerca San Raffaele SpA, Milan, Italy
}

Correspondence should be addressed to Dario Finazzi, finazzi@med.unibs.it

Received 17 June 2010; Accepted 27 September 2010

Academic Editor: Carlo Colosimo

Copyright (c) 2011 Emanuela Castiglioni et al. This is an open access article distributed under the Creative Commons Attribution License, which permits unrestricted use, distribution, and reproduction in any medium, provided the original work is properly cited.

\begin{abstract}
The capacity to act as an electron donor and acceptor makes iron an essential cofactor of many vital processes. Its balance in the body has to be tightly regulated since its excess can be harmful by favouring oxidative damage, while its deficiency can impair fundamental activities like erythropoiesis. In the brain, an accumulation of iron or an increase in its availability has been associated with the development and/or progression of different degenerative processes, including Parkinson's disease, while iron paucity seems to be associated with cognitive deficits, motor dysfunction, and restless legs syndrome. In the search of DNA sequence variations affecting the individual predisposition to develop movement disorders, we scanned by DHPLC the exons and intronic boundary regions of ceruloplasmin, iron regulatory protein 2, hemopexin, hepcidin and hemojuvelin genes in cohorts of subjects affected by Parkinson's disease and idiopathic neurodegeneration with brain iron accumulation (NBIA). Both novel and known sequence variations were identified in most of the genes, but none of them seemed to be significantly associated to the movement diseases of interest.
\end{abstract}

\section{Introduction}

Iron is an essential element for cells, but when in excess or not properly stored, it can be toxic by the Fenton reaction that generates reactive oxygen species. It is highly probable that an impaired iron metabolism exerts a role in the pathogenesis of different neurodegenerative processes sharing the common feature of an aberrant iron distribution in selective brain areas. This seems to hold true especially for movement disorders. It is known that regions of the brain that are associated with motor functions usually show higher iron levels than other areas [1] indicating the relevance of iron homeostasis for these cerebral sections. Increased total iron or at least increased non-ferritin-bound labile iron seems to be closely associated to Parkinson's disease (PD) $[2,3]$. This has been documented in the substantia nigra (SN) of PD patients by many authors and with varied technologies [4-7]. Furthermore, iron chelation by clioquinol or sequestration by ferritin overexpression [8] protected dopaminergic neurons from chemically induced degeneration, while mice on iron-rich diet show increased sensitivity to the MPTP treatment [9]. A solid support to 
the causal relationship between iron and the development of neurodegeneration comes also from the observation that different hereditary neurodegenerative pathologies characterized by extrapyramidal symptoms are associated with defects in genes involved in iron homeostasis; mutations in the genes coding for ferritin light chain (FTL) or for ceruloplasmin (CP) lead to adult-onset diseases termed neuroferritinopathy $[10,11]$ and aceruloplasminemia [12], respectively, both included in the neurodegeneration with brain iron accumulation (NBIA) group and characterized by excess deposit of iron, especially in the basal ganglia. Friedeich ataxia is linked to variations in the frataxin gene which codes for a mitochondrial protein presumably involved in iron-sulphur cluster assembly [13]. Different animal models have been recently described which further strengthen the idea that impairment of iron management may be an early event in the route leading to increased oxidative stress and neurodegeneration. Iron Regulatory Protein (IRP)-2 knock-out mice show ataxia, tremors, and bradykinesia [14], while mice heterozygous for the deletion of the FTH gene have an altered ferritin to iron ratio, as described also in the brain of PD patients $[15,16]$.

The large majority of PD and other movement disorders are idiopathic and not associated with mendelian inheritance; nonetheless, genetic and environmental factors surely influence the individual risk to develop these type of diseases. On the basis of the postulated contribution of iron maldistribution to the development of these pathologies, genes coding for proteins participating to systemic and cerebral iron management can be interesting targets for association studies aimed at defining allelic variants affecting the population susceptibility for movement disorders. This hypothesis has experimental support: for example, some polymorphisms and haplotypes of the CP [17], of the transferrin [18], and of the haptoglobin gene [19] were found to be significantly associated with PD in cohort studies, and it was suggested that they may contribute to iron-induced oxidative stress. On the other hand, the numerous studies on mutations of the hemochromatosis gene HFE in PD gave more conflicting results [20-24].

Here, we report the results from an extensive genetic analysis of some of the key genes of iron metabolism such as CP, IRP2, Hepcidin (HAMP), and Hemopexin (HPX), in a large cohort of PD patients and in a smaller group of idiopathic neurodegeneration with brain iron accumulation (NBIA) cases.

\section{Material and Methods}

2.1. Patients and Controls. DNA for PD patients and controls was provided from the DNA Bank of the Parkinson Institute, Istituti Clinici di Perfezionamento, Milan, Italy (http://www.parkinson.it/dnabank.html). PD patients were selected because they had a positive family history (firstdegree and/or second-degree relative affected) or had an early onset before 40 years of age. The clinical diagnosis of PD was established according to the UK Parkinson Disease Society Brain Bank criteria $[25,26]$. Patients with idiopathic NBIA were from Ospedale Galliera, Genova, and from the
Section of Internal Medicine, University of Verona, Italy. An informed consent to the use of the genomic DNA for research purposes was provided by all participants. The study was approved by the local Ethics Committee.

2.2. Mutation Scanning. The genes of interest were amplified with standard protocols with the primers described in the supplementary information (See Table 1SI in supplememtary material available online at doi: 10.4061/2011/827693). Prior to DHPLC analysis, heteroduplexes were obtained by denaturing the PCR-amplified products at $95^{\circ} \mathrm{C}$ for 5 min and cooling down to $56^{\circ} \mathrm{C}$ over one hour. DHPLC screening was performed on a WAVETM DNA Fragment Analysis System (Transgenomic, Omaha, NE, USA) at the temperatures indicated in the supplementary data (Table 1SD). Hetero- and homodimers analysis was carried out with an acetonitrile gradient formed by mixing buffers A $(0.1 \mathrm{M}$ TEAA) and B (0.1 M TEAA, 25\% acetonitrile). DNA samples with an altered DHPLC profile were re-amplified in a new PCR reaction, confirmed on an DHPLC run and analyzed by direct DNA sequencing. The nomenclature was established according to den Dunnen and Antonarakis, 2003.

\section{Results and Discussion}

3.1. Parkinson's Disease. We recently described the incidence of sequence variations in the genes coding for the heavy and light chains of ferritin [27] and for mitochondrial ferritin, (Castiglioni et al. [28]) in patients affected by PD and idiopathic NBIA, and these results are recapitulated in Tables 1 and 2. We extended our analyses to other genes involved in the management of iron balance and trafficking and associated with iron-related neurodegeneration in patients or animal models. The DHPLC scanning of the 19 exons of CP in 103 PD patients revealed 24 nucleotide substitutions, of which six were not reported in databases. Eleven of them were in the coding region, 1 in the $3^{\prime}$ UTR, and 12 in the introns (Table 1). Many of them (10) were rare, with an allelic frequency below $1 \%$. The $\mathrm{c}+1632 \mathrm{~A}>\mathrm{T}$ (D544E) substitution, which was previously found to be associated with PD [17], was detected at the heterozygous state in 10 patients $(4.85 \%)$. This frequency is not significantly different from that reported in dbSNP (http://www.ncbi.nlm.nih.gov/) for studies based on populations of European origin (Hap Map CEU 7.5\%) and similar to the one reported by Hochstrasser for the control population of 180 subjects. Only three intronic variations were found in more than $5 \%$ of the population. For two of them (IVS12-15delG and IVS15$12 \mathrm{~T}>\mathrm{C}$ ), the incidence was significantly lower than that reported in databases, based on a lower number of subjects. The relevance of such results needs to be confirmed in wider populations, even though very similar frequencies (18.2\%) were found for the same two substitutions in 11 patients with idiopathic NBIA.

The analysis of IRP2 gene in $50 \mathrm{PD}$ patients resulted in the identification of 7 DNA variations, one new and six already known. One lies in the $5^{\prime}$ UTR, 1 synonymous in exon 21, and 5 in the introns. Most of them were rare (below $2 \%)$, and the others had allelic frequencies similar to those 
TABLE 1: Allelic frequencies of the sequence variations identified in FTL, FTH, FTMT, CP, IRP2, HPX, and HAMP genes in PD patients and controls.

\begin{tabular}{|c|c|c|c|c|c|c|c|}
\hline \multirow{2}{*}{ Gene } & $\mathrm{PD}$ & $\mathrm{CNT}$ & \multirow{2}{*}{ DNA variation } & \multirow{2}{*}{ Gene position } & $\mathrm{AF}$ & $\mathrm{AF}$ & $\mathrm{AF}$ \\
\hline & $N$ & $N$ & & & $\mathrm{PD}$ & CNT & DB \\
\hline \multirow[t]{8}{*}{ FTL } & 252 & 180 & $c+163 \mathrm{~T}>\mathrm{C}$ & ex. 2 & $19.05 \%(96 / 504)$ & $25 \%(90 / 360)$ & $52 \%(1)$ \\
\hline & & & $c+522 C>T$ & ex. 4 & $0.20 \%(1 / 504)$ & none & \\
\hline & & & $c+398 \mathrm{~A}>\mathrm{C}(\mathrm{H} 133 \mathrm{P})$ & ex. 4 & $0.20 \%(1 / 504)$ & none & \\
\hline & & & c-129delC & IRE-L & $0.20 \%(1 / 504)$ & none & \\
\hline & & & $\mathrm{c}-37 \mathrm{~T}>\mathrm{C}$ & 5' UTR & $0.20 \%(1 / 504)$ & none & \\
\hline & & & IVS $2+50 \mathrm{C}>\mathrm{T}$ & int. 2 & $0.40 \%(2 / 504)$ & none & \\
\hline & & & $\mathrm{IVS} 2+60 \mathrm{~T}>\mathrm{G}$ & int. 2 & $0.40 \%(2 / 504)$ & $0.56 \%(2 / 360)$ & \\
\hline & & & IVS2+66G $>C$ & int. 2 & $0.20 \%(1 / 504)$ & none & \\
\hline \multirow[t]{3}{*}{ FTH } & 252 & 180 & $c+161 A>G(K 54 R)$ & ex. 2 & none & $0.56 \%(2 / 360)$ & \\
\hline & & & IVS2+29 ins GTCATAG2 & int. 2 & $3.57 \%(18 / 504)$ & $4.44 \%(16 / 360)$ & \\
\hline & & & IVS2+23 G>A & int. 2 & $0.20 \%(1 / 504)$ & none & \\
\hline \multirow[t]{7}{*}{ FTMT } & 332 & 342 & $c+134 \mathrm{C}>\mathrm{A}(\mathrm{P} 45 \mathrm{H})$ & ex.1. & $1.05 \%(7 / 664)$ & $2.49 \%(17 / 684)$ & \\
\hline & & & $\mathrm{c}+273 \mathrm{C}>\mathrm{T}$ (S91S) & ex.1 & $0.15 \%(1 / 664)$ & none & \\
\hline & & & $c+506 \mathrm{~A}>\mathrm{T}(\mathrm{N} 169 \mathrm{I})$ & ex.1 & none & $0.15 \%(1 / 684)$ & \\
\hline & & & $c+554 G>A(G 185 D)$ rs35482405 & ex.1 & $0.15 \%(1 / 664)$ & none & $1.5 \%(2)$ \\
\hline & & & $c+646 \mathrm{G}>C(\mathrm{~V} 216 \mathrm{~L})$ & ex.1 & $0.15 \%(1 / 664)$ & $0.29 \%(2 / 684)$ & \\
\hline & & & $c+667 G>T(A 223 S)$ & ex.1 & $0.15 \%(1 / 664)$ & $0.29 \%(2 / 684)$ & \\
\hline & & & $c+745 \mathrm{C}>\mathrm{T}$ & 3' UTR & $0.15 \%(1 / 664)$ & none & \\
\hline \multirow[t]{24}{*}{$\mathrm{CP}$} & 103 & none & $\mathrm{c}+484 \mathrm{~A}>\mathrm{T}(\mathrm{T} 162 \mathrm{~S})$ & ex. 3 & $0.49 \%(1 / 206)$ & & \\
\hline & & & $\mathrm{c}+788 \mathrm{~A}>\mathrm{G}(\mathrm{N} 263 \mathrm{~S})$ & ex. 5 & $0.49 \%(1 / 206)$ & & \\
\hline & & & $c+1430 \mathrm{C}>\mathrm{T}(\mathrm{P} 477 \mathrm{~L}) \mathrm{rs} 35331711$ & ex. 8 & $0.49 \%(1 / 206)$ & & $1.3 \%(2)$ \\
\hline & & & $\mathrm{c}+1632 \mathrm{~A}>\mathrm{T}(\mathrm{D} 544 \mathrm{E}) \mathrm{rs} 701753$ & ex. 9 & $4.85 \%(10 / 206)$ & & $7.5 \%(1)$ \\
\hline & & & $\mathrm{c}+1652 \mathrm{C}>\mathrm{T}(\mathrm{T} 551 \mathrm{I}) 3 \mathrm{rs} 61733458$ & ex. 9 & $4.37 \%(9 / 206)$ & & nd \\
\hline & & & $c+1950 A>C(G 650 G) r s 1053709$ & ex. 11 & $3.88 \%(8 / 206)$ & & $5.1 \%(1)$ \\
\hline & & & $c+2446 G>A(V 816 L)$ & ex. 14 & $0.49 \%(1 / 206)$ & & \\
\hline & & & $c+2522 C>G(T 841 R) 3$ rs56033670 & ex. 14 & $0.97 \%(2 / 206)$ & & nd \\
\hline & & & $\mathrm{c}+2571 \mathrm{C}>\mathrm{T}(\mathrm{Y} 857 \mathrm{Y})$ & ex. 15 & $0.49 \%(1 / 206)$ & & \\
\hline & & & $\mathrm{c}+2793 \mathrm{~A}>\mathrm{G}(\mathrm{L} 931 \mathrm{~L}) \mathrm{rs} 34987997$ & ex. 16 & $0.49 \%(1 / 206)$ & & $2.2 \%(3)$ \\
\hline & & & $\mathrm{c}+2991 \mathrm{~T}>\mathrm{C}(\mathrm{H} 997 \mathrm{H}) \mathrm{rs} 34394958$ & ex. 17 & $2.91 \%(6 / 206)$ & & $7.9 \%(3)$ \\
\hline & & & IVS1+41G >A rs3736282 & int. 1 & $6.31 \%(13 / 206)$ & & $11.4 \%(3)$ \\
\hline & & & IVS $2+20 \mathrm{C}>\mathrm{T}$ rs 17847023 & int. 2 & $4.85 \%(10 / 206)$ & & $10.9 \%(3)$ \\
\hline & & & IVS4-14C > T rs34067682 & int. 4 & $2.43 \%(5 / 206)$ & & $6.5 \%(3)$ \\
\hline & & & IVS5-51A $>$ G rs34003547 & int. 5 & $4.37 \%(9 / 206)$ & & $2.3 \%(3)$ \\
\hline & & & IVS7-47G $>A$ & int. 7 & $0.97 \%(2 / 206)$ & & \\
\hline & & & IVS9-38T >C rs6799507 & int. 9 & $1.46 \%(3 / 206)$ & & $0.8 \%(1)$ \\
\hline & & & IVS10+62T >C rs35149808 & int. 10 & $0.49 \%(1 / 206)$ & & $0.0 \%(3)$ \\
\hline & & & IVS10+113C $>$ T rs35516209 & int. 10 & $4.37 \%(9 / 206)$ & & $4.5 \%(3)$ \\
\hline & & & IVS14+17G>A rs35593818 & int. 14 & $3.88 \%(8 / 206)$ & & $6.2 \%(3)$ \\
\hline & & & IVS12-15delG rs34861155 & int. 12 & $17.96 \%(37 / 206)$ & & $36.4 \%(3)$ \\
\hline & & & IVS15-12T >C rs16861582 & int. 15 & $15.05 \%(31 / 206)$ & & $32.5 \%(1) .20 .8 \%(4)$ \\
\hline & & & IVS17-78T $>C$ & int. 17 & $0.49 \%(1 / 206)$ & & \\
\hline & & & $c+3335 C>T$ rs 34228141 & 3' UTR & $2.43 \%(5 / 206)$ & & \\
\hline \multirow[t]{7}{*}{ IRP2 } & 50 & none & $\mathrm{c}+2616 \mathrm{C}>\mathrm{T}(\mathrm{A} 872 \mathrm{~A}) \mathrm{rs} 13180$ & ex. 21 & $21 \%(21 / 100)$ & & $35 \%(1)$ \\
\hline & & & $c-89 \mathrm{C}>\mathrm{T} 4 \mathrm{rs} 954144$ & $5^{\prime}$ UTR & $28 \%(28 / 100)$ & & $44 \%(1)$ \\
\hline & & & IVS4-56G $>C$ & int. 4 & $2 \%(2 / 100)$ & & \\
\hline & & & IVS5+22A >C rs 2938672 & int. 5 & $1 \%(1 / 100)$ & & $0 \%(1)$ \\
\hline & & & IVS5+73delC rs11372841 & int. 5 & $1 \%(1 / 100)$ & & nd \\
\hline & & & IVS7+19A >G rs3817092 & int. 7 & $10 \%(10 / 100)$ & & $16.1 \%(1)$ \\
\hline & & & IVS12+50G >A rs 9788758 & int. 12 & $2 \%(2 / 100)$ & & nd \\
\hline
\end{tabular}


TABLE 1: Continued.

\begin{tabular}{|c|c|c|c|c|c|c|c|}
\hline \multirow{2}{*}{ Gene } & $\mathrm{PD}$ & $\mathrm{CNT}$ & \multirow{2}{*}{ DNA variation } & \multirow{2}{*}{ Gene position } & $\mathrm{AF}$ & $\mathrm{AF}$ & $\mathrm{AF}$ \\
\hline & $N$ & $N$ & & & $\mathrm{PD}$ & CNT & DB \\
\hline \multirow[t]{5}{*}{ HPX } & 103 & 94 & $\mathrm{c}+1017 \mathrm{C}>\mathrm{T}(\mathrm{S} 339 \mathrm{~S})$ & ex. 9 & None & $0.5 \%(1 / 188)$ & \\
\hline & & & IVS1+24C > T rs35862450 & int. 1 & $13.1 \%(27 / 206)$ & $19.7 \%(37 / 188)$ & \\
\hline & & & IVS1-32T >A & int. 1 & $1 \%(2 / 206)$ & None & $26.4 \%(5)$ \\
\hline & & & IVS1-41C>T & int. 1 & None & $0.5 \%(1 / 188)$ & \\
\hline & & & IVS8-26A>G & int. 8 & None & $0.5 \%(1 / 188)$ & \\
\hline \multirow[t]{2}{*}{ HAMP } & 50 & 50 & $c-72 C>T$ & & $1.0 \%(1 / 100)$ & None & \\
\hline & & & $\mathrm{c}+55 \mathrm{G}>\mathrm{A}(\mathrm{A} 19 \mathrm{~T})$ & ex 1 & $1.0 \%(1 / 100)$ & None & \\
\hline
\end{tabular}

Genomic DNA from PD patients and controls was PCR amplified and scanned by DHPLC. PD: Parkinson's disease, CNT: controls, AF: allelic frequency, DB: database.

FTL: ferritin light chain (NM_000146.3), FTH: ferritin heavy chain (NM_002032.2), FTMT: mitochondrial ferritin (NM_026286.2), CP: ceruloplasmin (NM_000096.3), IRP2: iron regulatory protein 2 (NM_004136.2), HPX: hemopexin (NM_000613.2), HAMP: hepcidin (NM_021175.2), ex: exon, int: intron, (1) HapMap-CEU, (2) AGI ASP POPULATION, (3) JAR CEPH-PANEL, (4) AFD EUR PANEL, (5) pilot1.CEU.

TABLE 2: Allelic frequencies of the sequence variations identified in CP and IRP-2 genes in sNFT patients.

\begin{tabular}{|c|c|c|c|c|c|c|}
\hline \multirow{2}{*}{ Gene } & \multirow{2}{*}{ NBIA } & \multirow{2}{*}{ DNA variation } & \multirow{2}{*}{ Gene position } & $\mathrm{AF}$ & $\mathrm{AF}$ & $\mathrm{AF}$ \\
\hline & & & & NBIA & CNT & DB \\
\hline FTL & 11 & $c+163 \mathrm{~T}>\mathrm{C}(\mathrm{L} 55 \mathrm{~L}) \mathrm{rs} 2230267$ & ex. 2 & $31.82 \%(7 / 22)$ & $25 \%(90 / 360)$ & $52 \%(1)$ \\
\hline FTH & 11 & $c+161 A>G(K 54 R)$ & ex. 2 & None & $0.56 \%(2 / 360)$ & \\
\hline FTMT & 11 & $\mathrm{c}+134 \mathrm{C}>\mathrm{A}(\mathrm{P} 45 \mathrm{H})$ & ex.1 & $4.55 \%(1 / 22)$ & $2.49 \%(17 / 684)$ & \\
\hline \multirow[t]{7}{*}{$\mathrm{CP}$} & 11 & $\mathrm{c}+1632 \mathrm{~A}>\mathrm{T}(\mathrm{D} 544 \mathrm{E}) \mathrm{rs} 701753$ & ex. 9 & $9.09 \%(2 / 22)$ & & $7.5 \%(1)$ \\
\hline & & $\mathrm{c}+1652 \mathrm{C}>\mathrm{T}(\mathrm{T} 551 \mathrm{I}) \mathrm{rs} 61733458$ & ex.9 & $4.55 \%(1 / 22)$ & & nd \\
\hline & & IVS1+41G>A rs3736282 & int. 1 & $13.64 \%(3 / 22)$ & & $11.4 \%(2)$ \\
\hline & & IVS2+20C $>$ T rs 17847023 & int. 2 & $18.2 \%(4 / 22)$ & & $10.9 \%(2)$ \\
\hline & & IVS10+91C > G rs41267873 & int. 10 & $4.55 \%(1 / 22)$ & & $0.0 \%(2)$ \\
\hline & & IVS12-15delG rs34861155 & int. 12 & $18.2 \%(4 / 22)$ & & $36.4 \%(2)$ \\
\hline & & IVS15-12T >C rs16861582 & int. 15 & $18.2 \%(4 / 22)$ & & $32.5 \%(1)$ \\
\hline \multirow[t]{2}{*}{ IRP2 } & 11 & $c-89 C>$ T rs 954144 & $5^{\prime}$ UTR & $22.95 \%(6 / 22)$ & & $44 \%(3)$ \\
\hline & & $\mathrm{c}+2616 \mathrm{C}>\mathrm{T}(\mathrm{A} 872 \mathrm{~A}) \mathrm{rs} 13180$ & ex. 21 & $21 \%(4 / 22)$ & & $35 \%(1)$ \\
\hline
\end{tabular}

Genomic DNA from idiopathic NBIA patients was PCR amplified and scanned by DHPLC. sNFT: suspected Neuroferritinopathies, AF: allelic frequency, DB: database.

FTL: ferritin light chain (NM_000146.3), FTH: ferritin heavy chain (NM_002032.2), FTMT: mitochondrial ferritin (NM_026286.2), CP: ceruloplasmin (NM_000096.3), IRP2: iron regulatory protein-2 (NM_004136.2), ex: exon, int = intron, (1) HapMap-CEU, (2) JAR CEPH-PANEL, (3) pilot1.CEU.

reported in databases. All the 10 exons of the HPX gene were analysed by DHPLC in 103 patients and 94 controls. We found 1 synonymous substitution in exon 9 and 4 in the introns. The IVS1+24C>T variation was common (mean allelic frequency 16.2\%) with no difference between patients and controls. All the other ones were rare, and the IVS1-32T $>$ A was clearly underrepresented when compared to available information in the database ( $1 \%$ versus $26,4 \%$ ). The study of the HAMP and HJV genes was limited to exon 1 and exons 2 and 3, respectively, due to problems with DNA amplification. However, these exons cover a significant portion of the coding sequence in both genes. No variation in the HJV gene was found in the 50 patients and 50 controls analysed, while 2 substitutions were found in HAMP gene, both in the patient group, 1 nonsynonymous change in exon $1(\mathrm{c}+55 \mathrm{G}>\mathrm{A}, \mathrm{A} 19 \mathrm{~T})$ and 1 at the base immediately preceding the transcription start site.

3.2. Idiopathic NBIA. Eleven cases of idiopathic NBIA were investigated for DNA sequence variations in the CP and IRP2 genes (Table 2). Seven different SNPs were detected in CP; all of them were already described and had frequencies not significantly different from the ones we found in PD patients or available in the database. Only the intronic substitution IVS $2+20 \mathrm{C}>\mathrm{T}$ was more frequent than expected since 4 out of 11 patients were heterozygous for it $(18,2 \%)$ as compared to the $4.85 \%$ frequency in the PD cohort and the $10,9 \%$ in the database. In the IRP2 gene, only two variations were found $(c-89 \mathrm{C}>\mathrm{T}, \mathrm{c}+2616 \mathrm{C}>\mathrm{T})$ and with frequencies comparable to those found in PD patients.

\section{Conclusion}

Homozygous mutations of CP, IRP2, and HPX were found to cause neurodegeneration in patients [12] or in animal models [14] and Morello et al. [29]. Here, we show that these genes present DNA variations and polymorphisms, but none of them has an allelic frequency, which allows us to infer a possible effect upon the individual risk to develop the disease. Also the $\mathrm{c}+1632 \mathrm{~A}>\mathrm{T}$ (D544E) substitution in the CP gene, 
which has been found to be linked to PD and to increased echogenicity of the SN [17], does not appear to be differently present in our PD population than in-database studies. HAMP and HJV encode proteins with a central role in the regulation of systemic iron homeostasis and show some DNA variations, but none of them is evidently associated with $\mathrm{PD}$ disorders. As for idiopathic NBIA, our cohort was very small and the data limited, but they do not suggest an evident association of DNA variations in CP and IRP2 genes with such disorders. Even though iron metabolism probably exerts an important role in the development of the neurodegenerative processes which underline several types of movement disorders, the genetic data we generated until now seem to exclude a simple and direct involvement of key genes of iron management in modifying the individual predisposition to PD and NBIA. More in depth studies are required to verify the existence of more complex genetic interactions that could link some of the identified nucleotide variations with brain iron deregulation and neurodegeneration.

\section{Acknowledgments}

The authors thank the Human Genetic Bank of Patients affected by Parkinson Disease and parkinsonism (http:// parkinson.it/dnabank.html) of the Telethon Genetic Biobank Network (http://www.biobanknetwork.org/) supported by TELETHON Italy (project no. GTB07001) and by Fondazione Grigioni per il Morbo di Parkinson and the Bank for the Diagnosis and Research of Movement Disorders (MDB) of the EuroBiobank (http://www.eurobiobank.org/). The paper was partially supported by Telethon Grant GGP05141 to PA and LC. Emanuela Castiglioni and Dario Finazzi equally contributed to the work.

\section{References}

[1] A. H. Koeppen, "The history of iron in the brain," Journal of the Neurological Sciences, vol. 134, no. 1, pp. 1-9, 1995.

[2] A. Friedman, J. Galazka-Friedman, and D. Koziorowski, "Iron as a cause of Parkinson disease — a myth or a well established hypothesis?" Parkinsonism and Related Disorders, vol. 15, supplement 3, pp. S212-S214, 2009.

[3] L. Zecca, M. B. H. Youdim, P. Riederer, J. R. Connor, and R. R. Crichton, "Iron, brain ageing and neurodegenerative disorders," Nature Reviews Neuroscience, vol. 5, no. 11, pp. 863-873, 2004.

[4] D. T. Dexter, A. Carayon, F. Javoy-Agid et al., "Alterations in the levels of iron, ferritin and other trace metals in Parkinson's disease and other neurodegenerative diseases affecting the basal ganglia," Brain, vol. 114, no. 4, pp. 1953-1975, 1991.

[5] P. Riederer, E. Sofic, W.-D. Rausch et al., "Transition metals, ferritin, glutathione, and ascorbic acid in parkinsonian brains," Journal of Neurochemistry, vol. 52, no. 2, pp. 515-520, 1989.

[6] E. Sofic, P. Riederer, H. Heinsen et al., "Increased iron (III) and total iron content in post mortem substantia nigra of parkinsonian brain," Journal of Neural Transmission, vol. 74, no. 3, pp. 199-205, 1988.

[7] L. Zecca, A. Stroppolo, A. Gatti et al., "The role of iron and molecules in the neuronal vulnerability of locus coeruleus and substantia nigra during aging," Proceedings of the National Academy of Sciences of the United States of America, vol. 101, no. 26, pp. 9843-9848, 2004.

[8] D. Kaur, F. Yantiri, S. Rajagopalan et al., "Genetic or pharmacological iron chelation prevents MPTP-induced neurotoxicity in vivo: a novel therapy for Parkinson's disease," Neuron, vol. 37, no. 6, pp. 899-909, 2003.

[9] A. Fredriksson, N. Schröder, P. Eriksson, I. Izquierdo, and T. Archer, "Neonatal iron potentiates adult MPTP-induced neurodegenerative and functional deficits," Parkinsonism and Related Disorders, vol. 7, no. 2, pp. 97-105, 2001.

[10] A. R. J. Curtis, C. Fey, C. M. Morris et al., "Mutation in the gene encoding ferritin light polypeptide causes dominant adult-onset basal ganglia disease," Nature Genetics, vol. 28, no. 4, pp. 350-354, 2001.

[11] S. Levi, A. Cozzi, and P. Arosio, "Neuroferritinopathy: a neurodegenerative disorder associated with L-ferritin mutation," Best Practice and Research: Clinical Haematology, vol. 18, no. 2, pp. 265-276, 2005.

[12] X. Xu, S. Pin, M. Gathinji, R. Fuchs, and Z. L. Harris, "Aceruloplasminemia: an inherited neurodegenerative disease with impairment of iron homeostasis," Annals of the New York Academy of Sciences, vol. 1012, pp. 299-305, 2004.

[13] T. A. Rouault and W. H. Tong, "Iron-sulfur cluster biogenesis and human disease," Trends in Genetics, vol. 24, no. 8, pp. 398407, 2008.

[14] T. LaVaute, S. Smith, S. Cooperman et al., "Targeted deletion of the gene encoding iron regulatory protein-2 causes misregulation of iron metabolism and neurodegenerative disease in mice," Nature Genetics, vol. 27, no. 2, pp. 209-214, 2001.

[15] C. Borie, F. Gasparini, P. Verpillat et al., "Association study between iron-related genes polymorphisms and Parkinson's disease," Journal of Neurology, vol. 249, no. 7, pp. 801-804, 2002.

[16] K. Thompson, S. Menzies, M. Muckenthaler et al., "Mouse brains deficient in $\mathrm{H}$-ferritin have normal iron concentration but a protein profile of iron deficiency and increased evidence of oxidative stress," Journal of Neuroscience Research, vol. 71, no. 1, pp. 46-63, 2003.

[17] H. Hochstrasser, P. Bauer, U. Walter et al., "Ceruloplasmin gene variations and substantia nigra hyperechogenicity in Parkinson disease," Neurology, vol. 63, no. 10, pp. 1912-1917, 2004.

[18] C. Borie, F. Gasparini, P. Verpillat et al., "Association study between iron-related genes polymorphisms and Parkinson's disease," Journal of Neurology, vol. 249, no. 7, pp. 801-804, 2002.

[19] P. Costa-Mallen, H. Checkoway, A. Zabeti et al., "The functional polymorphism of the hemoglobin-binding protein haptoglobin influences susceptibility to idiopathic Parkinson's disease," American Journal of Medical Genetics Part B, vol. 147, no. 2, pp. 216-222, 2008.

[20] N. Akbas, H. Hochstrasser, J. Deplazes et al., "Screening for mutations of the HFE gene in Parkinson's disease patients with hyperechogenicity of the substantia nigra," Neuroscience Letters, vol. 407, no. 1, pp. 16-19, 2006.

[21] G. Biasiotto, S. Goldwurm, D. Finazzi et al., "HFE gene mutations in a population of Italian Parkinson's disease patients," Parkinsonism and Related Disorders, vol. 14, no. 5, pp. 426-430, 2008.

[22] D. D. Buchanan, P. A. Silburn, J. B. Chalk, D. G. Le Couteur, and G. D. Mellick, "The Cys282Tyr polymorphism in the HFE gene in Australian Parkinson's disease patients," Neuroscience Letters, vol. 327, no. 2, pp. 91-94, 2002. 
[23] M. C. J. Dekker, P. C. Giesbergen, O. T. Njajou et al., "Mutations in the hemochromatosis gene (HFE), Parkinson's disease and parkinsonism," Neuroscience Letters, vol. 348, no. 2, pp. 117-119, 2003.

[24] R. J. Guerreiro, J. M. Bras, I. Santana et al., "Association of HFE common mutations with Parkinson's disease, Alzheimer's disease and mild cognitive impairment in a Portuguese cohort," BMC Neurology, vol. 6, article 24, 2006.

[25] A. J. Hughes, S. E. Daniel, L. Kilford, and A. J. Lees, "Accuracy of clinical diagnosis of idiopathic Parkinson's disease: a clinico-pathological study of 100 cases," Journal of Neurology Neurosurgery and Psychiatry, vol. 55, no. 3, pp. 181-184, 1992.

[26] A. J. Hughes, S. E. Daniel, and A. J. Lees, "Improved accuracy of clinical diagnosis of Lewy body Parkinson's disease," Neurology, vol. 57, no. 8, pp. 1497-1499, 2001.

[27] B. Foglieni, F. Ferrari, S. Goldwurm et al., "Analysis of ferritin genes in Parkinson disease," Clinical Chemistry and Laboratory Medicine, vol. 45, no. 11, pp. 1450-1456, 2007.

[28] E. Castiglioni, D. Finazzi, S. Goldwurm et al., "Sequence variations in mitochondrial ferritin: distribution in healthy controls and different types of patients," Genet Test Mol Biomarkers, 2010. In press.

[29] N. Morello, E. Tonoli, F. Logrand et al., "Haemopexin affects iron distribution and ferritin expression in mouse brain," Journal of Cellular and Molecular Medicine, vol. 13, pp. 419241204, 2009. 


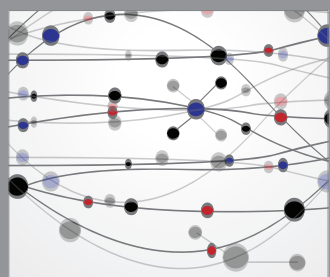

The Scientific World Journal
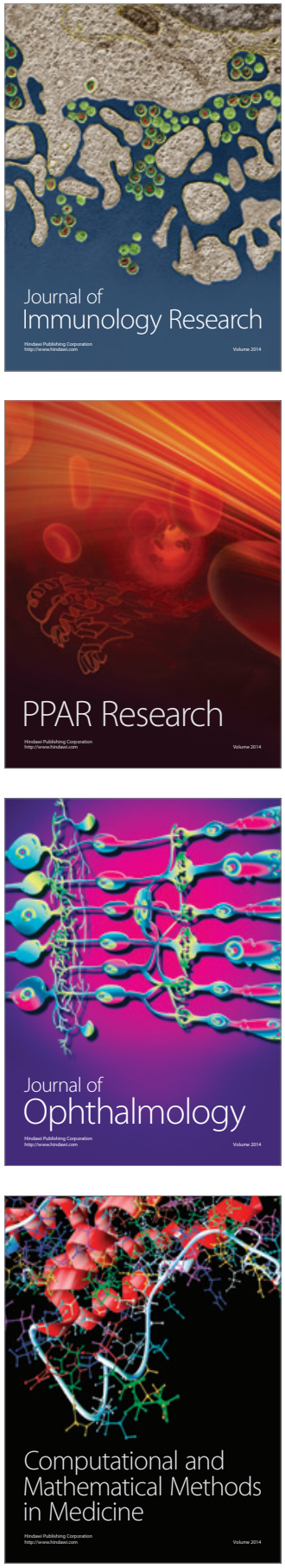

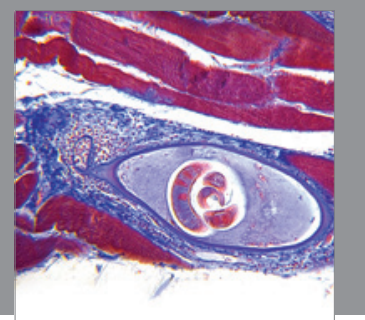

Gastroenterology

Research and Practice
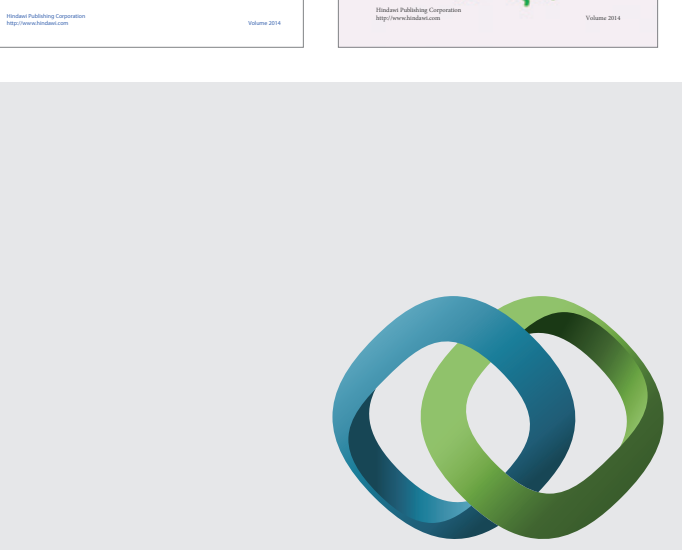

\section{Hindawi}

Submit your manuscripts at

http://www.hindawi.com
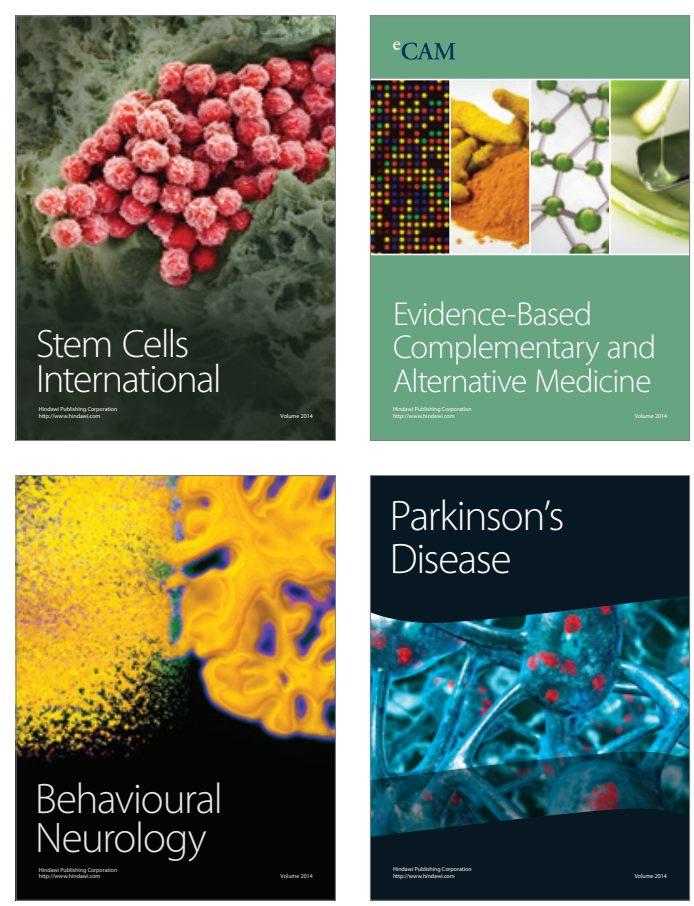

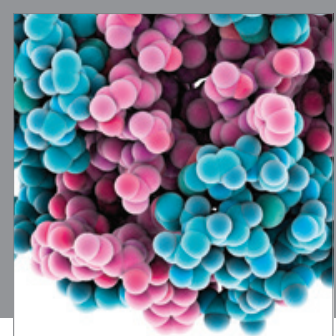

Journal of
Diabetes Research

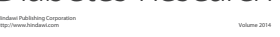

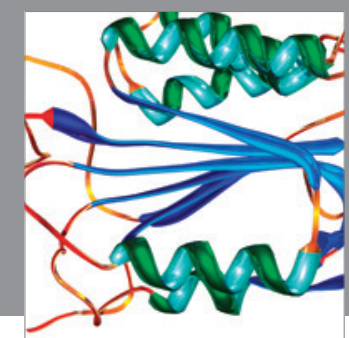

Disease Markers
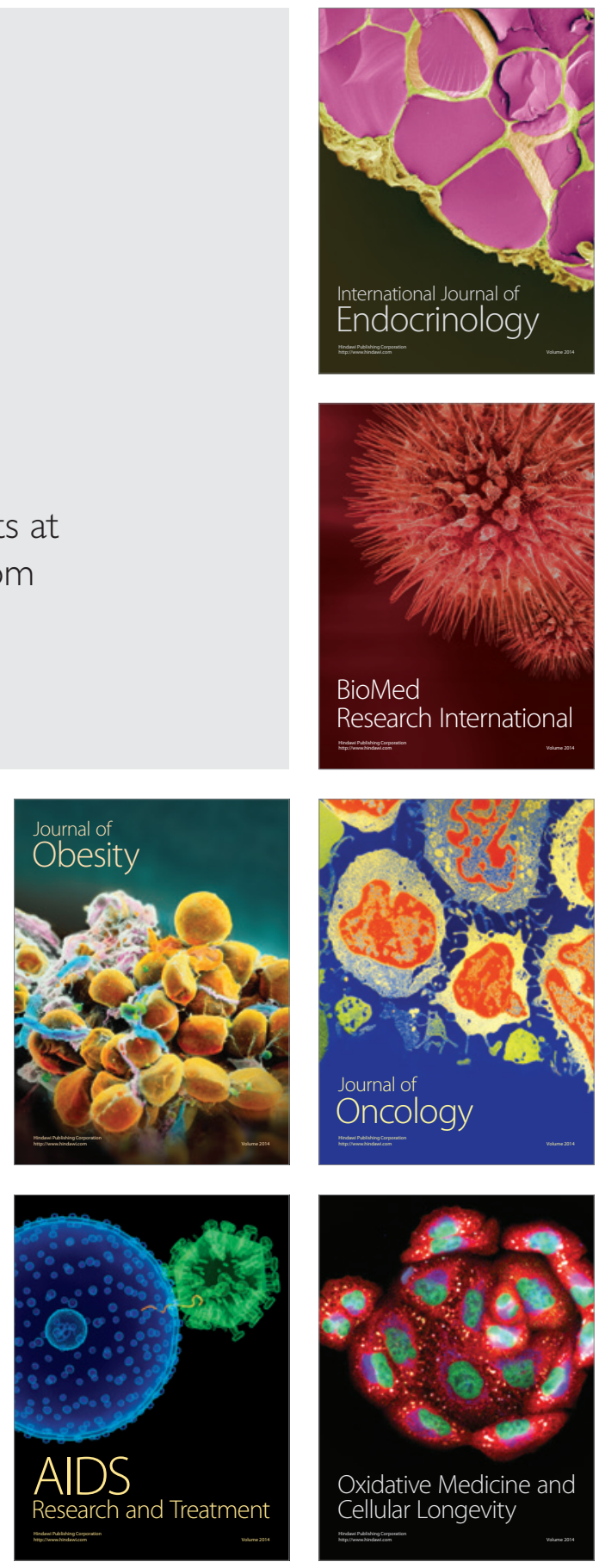